\title{
Numerical Investigation of School Stratified Ventilation Systems - A Ventilation Effectiveness Study
}

\author{
Mohammad Reza Adili ${ }^{1, *}$, Simon Engstfeld ${ }^{1}$, and Konstantinos Stergiaropoulos ${ }^{1}$ \\ ${ }^{1}$ University of Stuttgart, Institute for Building Energetics, Thermotechnology and Energy Storage, Pfaffenwaldring 35, 70569 Stuttgart, \\ Germany
}

\begin{abstract}
Good indoor air quality is an essential prerequisite for a healthy learning environment. Scientific research has shown that there is a direct correlation between air quality and pupils' ability to learn. For the same supply air volume flow, stratified ventilation systems lead to an improved quality of breathing air than mixing ventilation systems. The ventilation systems that work on the stratified ventilation principle are therefore particularly suitable for the ventilation of classrooms. The air flow characteristics of these systems in classrooms are, however, not thoroughly investigated. In the context of this work, the air flow parameters of various school ventilation systems with stratified ventilation for a typical classroom will be investigated by means of Computational Fluid Dynamics (CFD). For this purpose, centralized ventilation systems with different air outlets as well as decentralized systems are examined and compared regarding their ventilation effectiveness and thermal comfort.
\end{abstract}

\section{Introduction}

Through the concept of all-day school in Germany, children, adolescents and teachers spend more time in school buildings than previous generations. Therefore, a good indoor air quality is becoming increasingly important in order to create a healthy learning climate. Intensive renovation and new construction measures are required for the expansion of all-day schools, which are often accompanied by high insulation and air tightness measures in order to comply with the energy-related standards. High requirements on the airtightness of the building envelope lead to a reduction of infiltration. In modern classrooms with manual window ventilation, there is therefore reduced air quality, which has a negative impact on the learning ability of the students. Various studies confirm this and identify high $\mathrm{CO}_{2}$ concentrations as the main reason for unhygienic and unhealthy learning environments $[1,2]$.

An in-depth study and identification of suitable school ventilation systems is therefore essential to assist builders and designers in decision-making.

The adaptation of the highly efficient technology of stratification ventilation could lead to an improved indoor air quality in classrooms.

The use of stratified ventilation systems in rooms with particularly high occupancy, such as Classrooms has not yet been studied sufficiently to replace the mixing ventilation systems. Although with at least the same breathing air quality, the outdoor air rate of stratified ventilation systems can be reduced compared to mixing ventilation systems [3]. The current state of research, however, makes it clear that there is still an increased need for research in order to develop a deeper understanding of the influencing factors of air flow.

The present work therefore investigates the subject of school ventilation systems with stratified ventilation in more detail. For this purpose, different systems will be compared with regard to the ventilation effectiveness and the criteria for thermal comfort according to ISO 7730 [4] in a typical German classroom. Based on the results, recommendations for air distribution in schools can be formulated. Furthermore, an improvement of the systems is possible.

\section{Methods}

The modelled classroom, as shown in Fig. 1, has a net floor area of $60 \mathrm{~m}^{2}$.

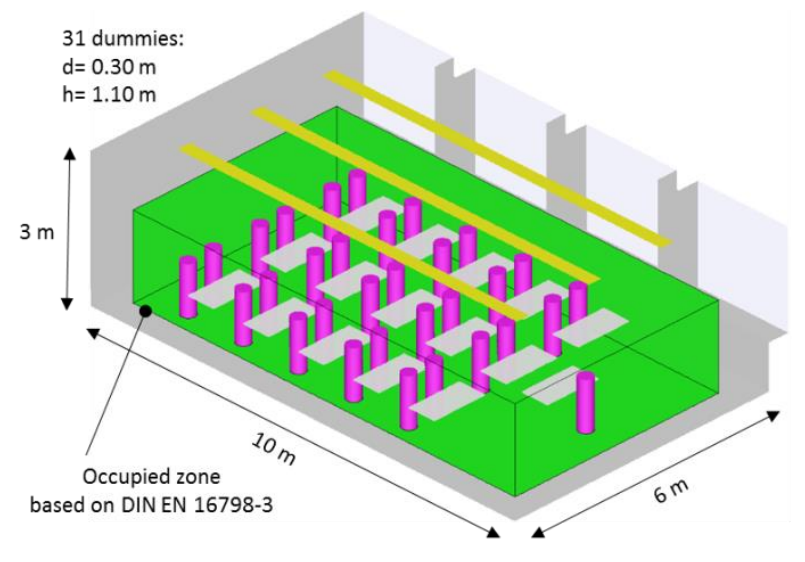

Fig. 1. 3D representation of the model.

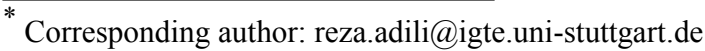


In total, there are 30 pupils and a teacher in the room. The outer wall consists of a parapet, on which the four outer windows are arranged. Opposite the outer wall is the corridor wall. Behind the teacher is the blackboard wall, which is located opposite the front wall. The occupied zone complies with the specifications of EN 16798-3 [5].

\subsection{Boundary Conditions}

The cylindrical dummies represent the seated students in the room. The heat dissipation of the dummies and their $\mathrm{CO}_{2}$ emission have been assumed as $91 \mathrm{~W}$ and $19 \mathrm{l} / \mathrm{h}$ respectively according to VDI 6040 [6]. The design of the outdoor air flow, which corresponds to the supply air, is carried out according to the recommendations of the EN 15251 [7] for the category II. A supply air volume of 932 $\mathrm{m}^{3} / \mathrm{h}$ is required for the ventilation of the classroom. All of the examined stratification systems have heat recovery with a heat recovery coefficient of 0.75 . Assuming that the outside air temperature in winter is $12{ }^{\circ} \mathrm{C}$ and the inside temperature $22{ }^{\circ} \mathrm{C}$, the supply air temperature is $16.5^{\circ} \mathrm{C}$. It is assumed that the supply air flows into the classroom with a $\mathrm{CO}_{2}$ concentration of 0 ppm. The given $\mathrm{CO}_{2}$ concentrations are therefore the $\mathrm{CO}_{2}$ concentration above that of the outside air. The corridor wall adjoins a heated hall with $15^{\circ} \mathrm{C}$. The insulation requirements of the EnEV [8] correspond to the outer wall. Even without heating system, the energy balance for the winter is achieved.

\subsection{Studied Cases}

The numerical investigation of the stratified ventilation systems from Fig. 2 and 3 took place within the work. All stratification systems are based on commercially available components.
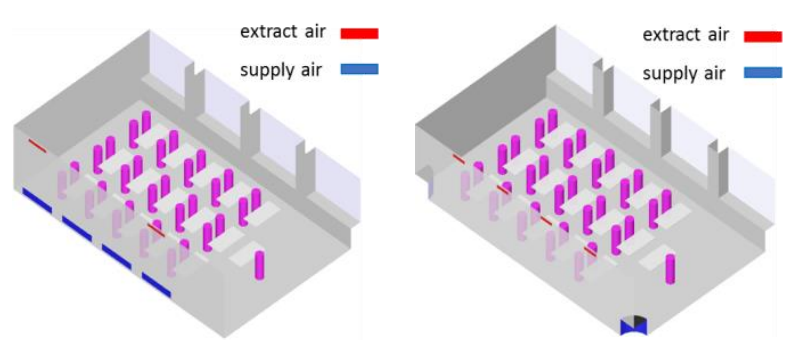

Wall mounted diffuser (WD)

Quarter round diffuser (QD)

Fig. 2. Schematic representation of the examined centralized systems.

\subsection{Numerical Study}

The numerical study of the classroom is performed with the CFD program ANSYS Fluent 17.1. With an unstructured mesh, which is refined in the areas with strong gradients, the spatial discretization takes place. A $\mathrm{k}-\varepsilon$ two-equation model is used for turbulence modelling. The fluid mixture of the room air is composed of air and
$\mathrm{CO}_{2}$. The numerical investigation is carried out for the steady state condition.

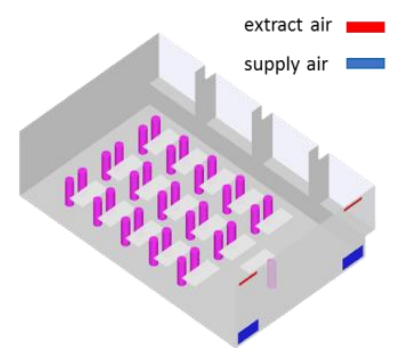

Stand mounted unit (SU)

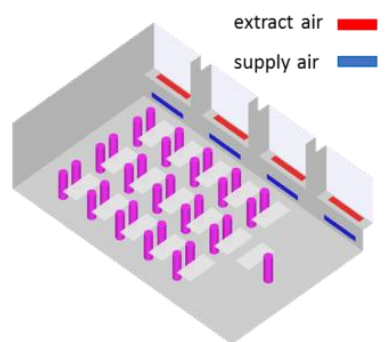

Horizontal unit (HU)

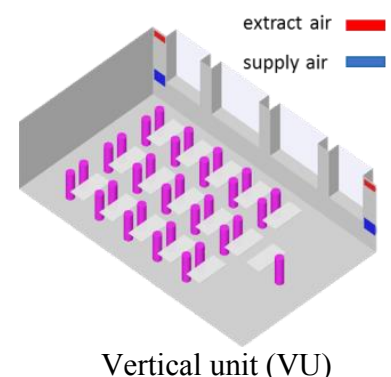

Fig. 3. Schematic representation of the examined decentralized systems.

\subsection{Evaluation Criteria}

On the basis of the pollutant removal performance and the thermal comfort criteria according to ISO 7730, a comparison of the studied ventilation cases takes place. The quantification of pollutant removal is possible by means of the Contaminant Removal Effectiveness, which is an assessment of ventilation effectiveness. The Contaminant Removal Effectiveness can be determined for different room areas and sectional planes. Thus, for example, the contaminant removal effectiveness of the occupied zone according to equation (1) is defined as the ratio between the steady state concentration of contaminant at the exhaust air, $c_{e}$, and the average steady state concentration in the occupied zone, $\bar{c}_{O Z}$ [9].

$$
\varepsilon_{o z}=\frac{c_{e}}{\bar{c}_{o Z}}
$$

The evaluation of the stratified ventilation systems is based on the categorization according to EN 15251 and the ISO 7730. According to the specifications of VDI 6040 and EN 15251, ventilation systems for schools are to be interpreted as a normal level of expectations, which corresponds to category II. As a result, category II is considered to be the minimum benchmark for which $\mathrm{CO}_{2}$ concentrations up to a maximum of $500 \mathrm{ppm}$ are permitted relative to the outdoor air concentration. 


\section{Results}

The stratified ventilation system with heat recovery for the wall mounted outlet (WD), the quarter-round displacement ventilation outlet (QO), the stand mounted unit (SU), the horizontal undersill unit (HU) and the vertical unit (VU) are studied under extreme winter condition for the fully occupied room.

With the vertical unit, there is an increased risk of draught for the teacher and the students in the middle of the fifth row. In Fig. 5 these areas are shown in red, since the draught rate is outside of the range of category III. In addition, the stratification layer is only conditionally stable (see Fig. 4) which leads to a low contaminant removal effectiveness with $\varepsilon_{O Z}=1.38$.

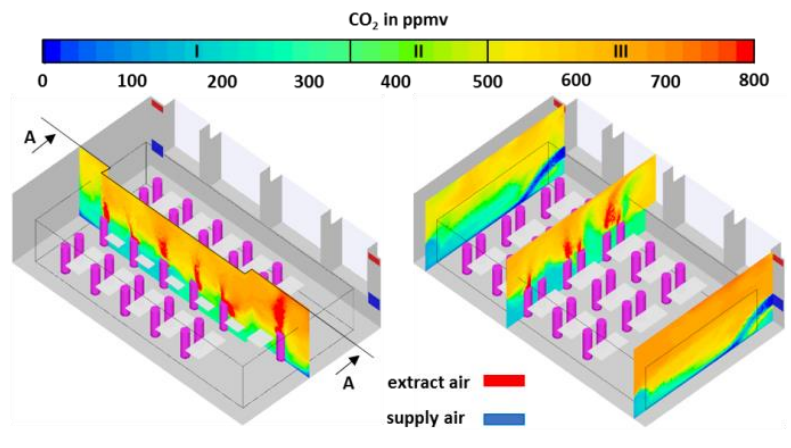

Fig. 4. $\mathrm{CO}_{2}$ concentration of the vertical unit: offset longitudinal section (1.) and the cross section (r.).

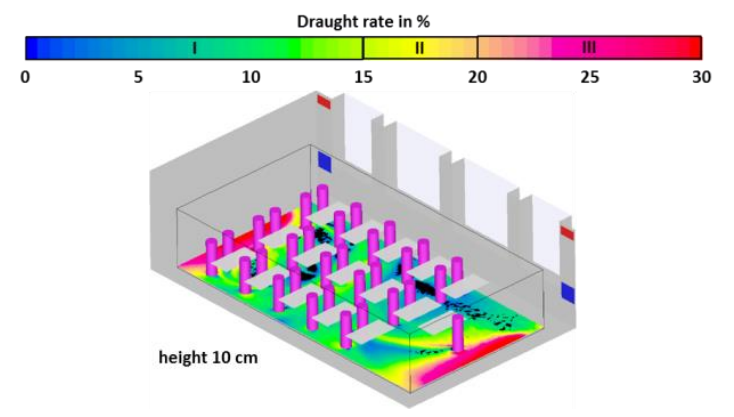

Fig. 5. Draught rate of the vertical unit.

In the case of the horizontal undersill unit, a stratified layer of insufficient height is formed due to the arrangement of the extract air outlets in the window sill, as shown in Fig. 6. Although this ensures a good ventilation effectiveness of $\varepsilon_{o z}=1.66$, the average $\mathrm{CO}_{2}$ concentrations of the horizontal sections in the standing and seated head height are clearly too high at around 570 ppm, as shown in Fig. 6.

The variant therefore only works according to the quasistratified ventilation principle, whose average vertical temperature gradient of $3.7 \mathrm{~K} / \mathrm{m}$ only meets the requirements of category III.

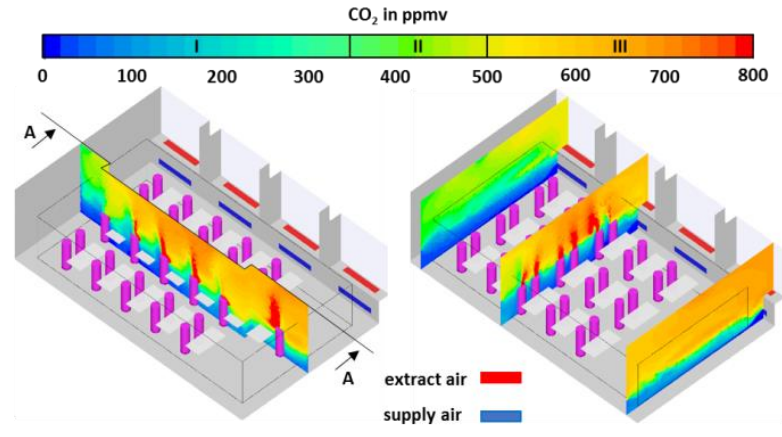

Fig. 6. $\mathrm{CO}_{2}$ concentration of the horizontal undersill unit: offset longitudinal section (1.) and the cross section (r.).

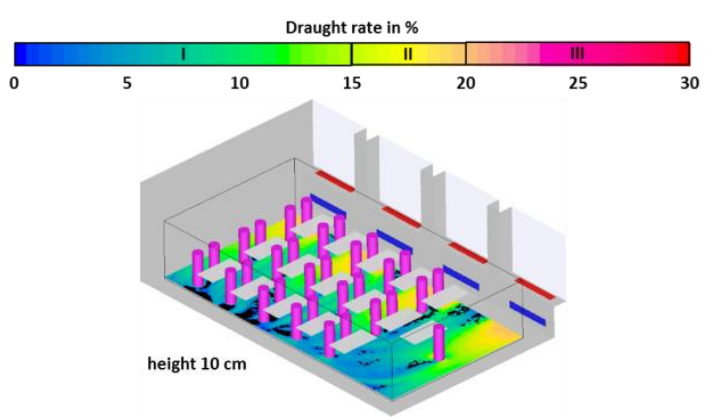

Fig. 7. Draught rate of the horizontal undersill unit.

For the winter case, however, the stratified ventilation system of the wall outlet is very well suited for the ventilation of classrooms. Good properties with few restrictions could be demonstrated for the quarter-round displacement ventilation outlet. This also applies to the slightly worse version of the standing unit.

Due to the large supply air area of the wall outlets, the most stable layer boundary in the classroom is formed, as shown in Fig. 8.

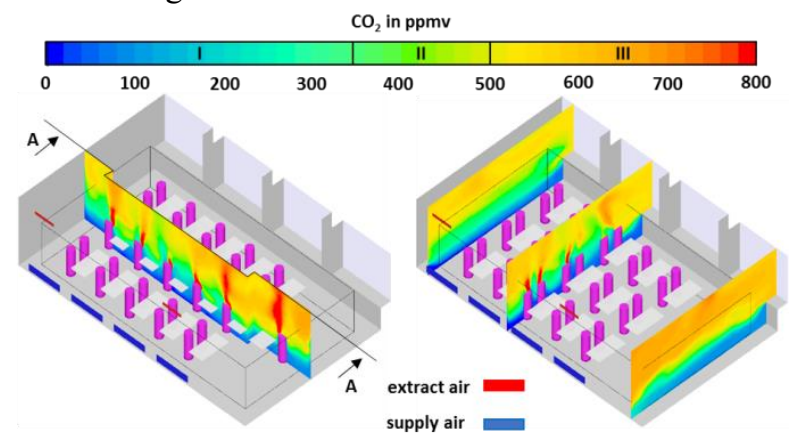

Fig. 8. $\mathrm{CO}_{2}$ concentration of the wall outlets: offset longitudinal section (1.) and the cross section (r.).

As a consequence, a very good ventilation effectiveness of $\varepsilon_{o z}=1.76$ is established. This provides the lowest average $\mathrm{CO}_{2}$ concentrations in the occupied zone, which corresponds to $338 \mathrm{ppm}$ of category I. Minor constraints exist for the draft risk and the average vertical temperature gradient which can be compensated with modified sitting arrangement in order to fulfil category II classification see Fig. 9. 


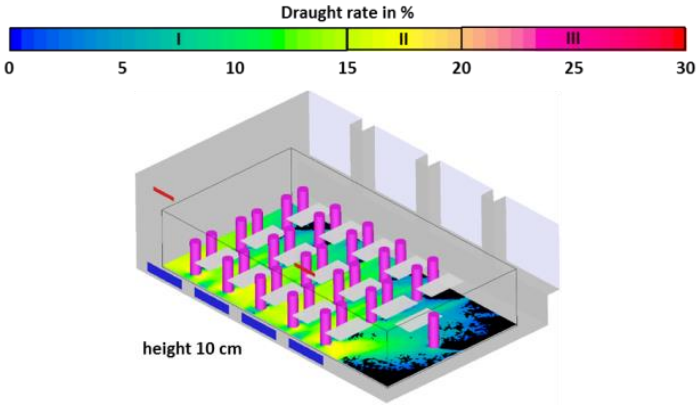

Fig. 9. Draught rate of the wall outlets.

The quarter-round displacement ventilation outlets have a slightly more unstable layer boundary than the wall outlets, as shown in Fig. 10. The ventilation effectiveness is therefore slightly reduced. Nevertheless, good values are achieved with $\varepsilon_{o z}=1.58$. It sets an average $\mathrm{CO}_{2}$ concentration of $379 \mathrm{ppm}$ in the occupied zone. This corresponds to Category II.

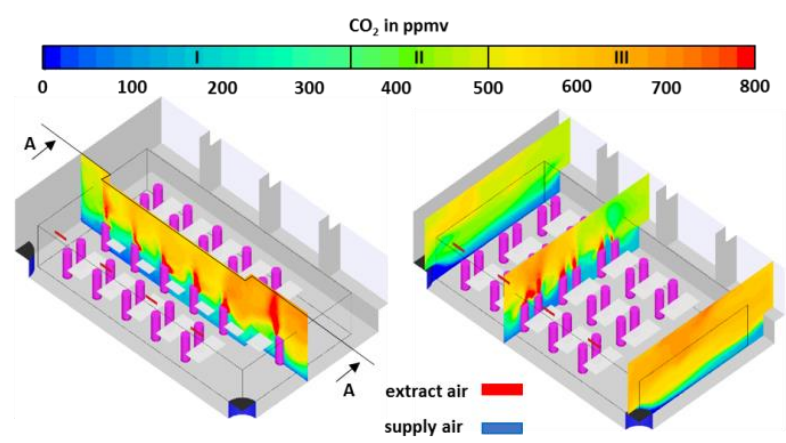

Fig. 10. $\mathrm{CO}_{2}$ concentration of the quarter-round displacement ventilation outlets: offset longitudinal section (1.) and the cross section (r.).

The maximum draft risk is $27 \%$, as shown in Fig. 11. However, adjusted seating arrangements are likely to qualify for category II. The average vertical temperature gradient complies with the requirements of category II, as is the case with the following standing unit.

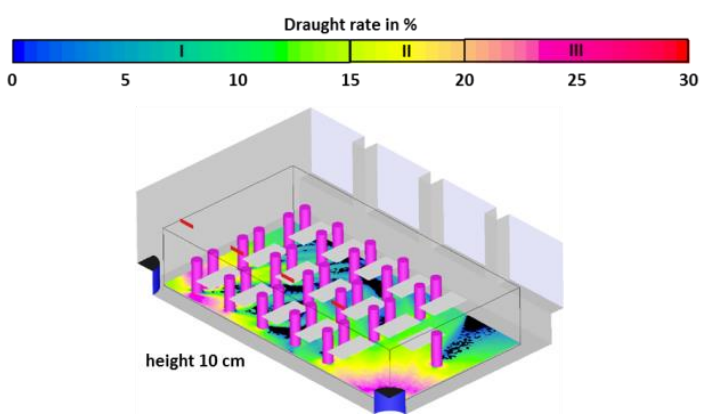

Fig. 11. Draught rate of the quarter-round displacement ventilation outlets.

The integration of two standing units in the blackboard wall area is well suited for the ventilation of classrooms. The decentralized devices are particularly easy to integrate in schools to be renovated. Fig. 12 shows a stable layer boundary. The ventilation effectiveness is $\varepsilon_{O Z}=$
1.61. The average $\mathrm{CO}_{2}$ concentration in the occupied zone is 377 ppm, which corresponds to Category II. With 506 ppm, the standing units achieve best values for the average $\mathrm{CO}_{2}$ concentration in the standing head height, which is just slightly above the category II limit.

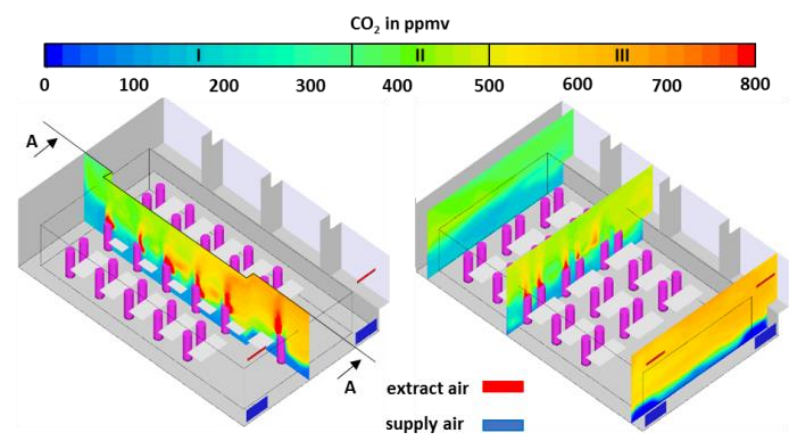

Fig. 12. $\mathrm{CO}_{2}$ concentration of the standing ventilation units: offset longitudinal section (1.) and the cross section (r.).

However, the draft risk is significantly higher at $27 \%$, as Fig. 13 shows. An adjustment of the seating arrangement is not possible, so that the variant represents the third best stratification ventilation system despite the good pollutant removal.

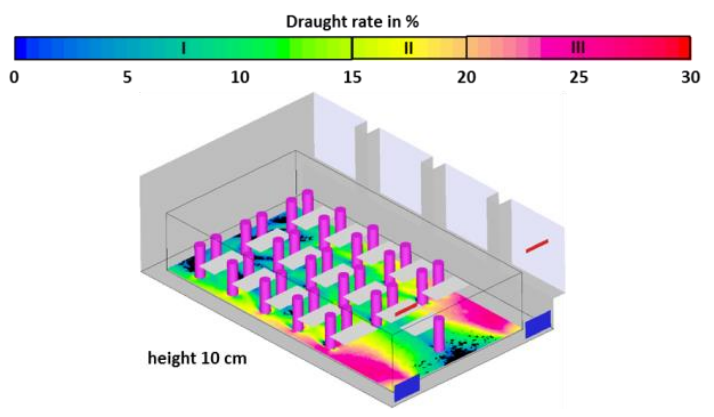

Fig. 13. Draught rate of the stand mounted ventilation units.

\section{Discussions}

In the evaluation of the results, the contaminant removal effectiveness and the draft risk are particularly important. The results show that the average contaminant removal effectiveness in the occupied zone is greater than one in all cases. Thus, all stratified ventilation systems have improved the pollutant removal compared to mixing ventilation systems $\left(\varepsilon_{o z}=1\right)$. Furthermore, all cases have the average $\mathrm{CO}_{2}$ concentration of less than $500 \mathrm{ppm}$ in the seated head height according to the stratified ventilation principle. The latter value is the design value according to EN 15251 for category II, which was originally considered for mixing ventilation. For this reason, stratified ventilation systems have a better pollutant removal performance than mixing ventilation systems. However, in all studied cases, average $\mathrm{CO}_{2}$ concentrations of more than 500 ppm occur in the standing head height (see Fig 14). This is a non-determinant criterion that is not critical to the classification of the systems because the people in the room perform predominantly sedentary activities. 


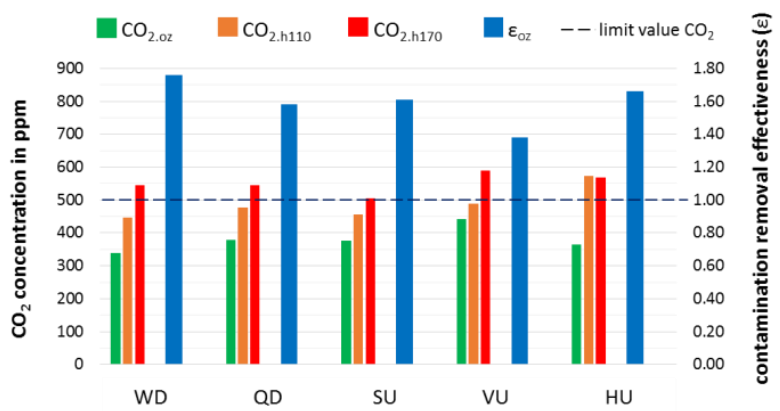

Fig. 14. Comparison of results for average $\mathrm{CO}_{2}$ concentration and Contaminant Removal Effectiveness.

The evaluation of the results shows that none of the systems fulfils all requirements for category II of thermal comfort according to EN 15251, because the Category II limits are partially exceeded, as shown in Figure 14 and Figure 15. As mentioned above, all the stratified ventilation systems have slightly higher average $\mathrm{CO}_{2}$ concentrations in the standing head height. In addition, the Predicted Percentage of Dissatisfied (PPD) of all systems in winter exceeds the limit. This is due to the low supply air temperature of $16.5{ }^{\circ} \mathrm{C}$, which makes occupants experience the indoor climate as slightly cool.

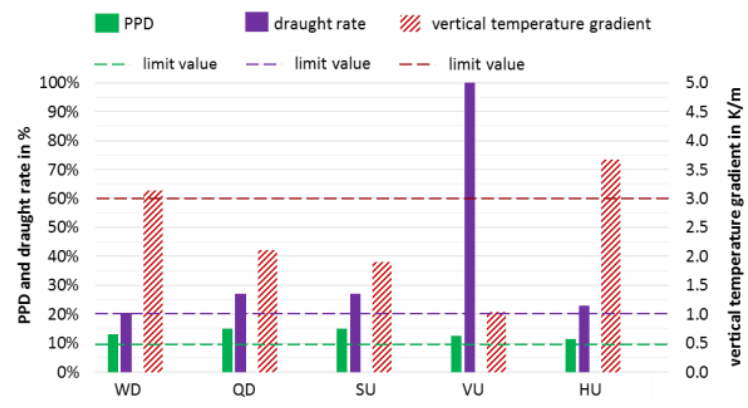

Fig. 15. Comparison of results for PPD, draught rate and vertical temperature gradient.

The decentralized stratified ventilation system of the horizontal unit is unsuitable for classroom ventilation in the selected configuration when compared to the other stratification systems.

Centralized stratified ventilation systems such as the wall outlet and the quarter-round displacement ventilation outlet lead to a slightly better indoor air quality in classrooms than decentralized systems, such as the standing and the horizontal undersill unit. For the integration of centralized systems, however, more construction measures for the course of the air duct network are to be made. Therefore, the use of these systems only in new school constructions is recommended. By contrast, decentralized systems are particularly suitable for retrofitting in school classrooms that are to be renovated, since the room-by-room integration is very simple.

\section{Summary and outlook}

The air flow characteristics of stratified ventilation systems in classrooms are currently not thoroughly investigated. In the present work, different commercially available centralized and decentralized stratified ventilation systems are compared with regard to the ventilation effectiveness and the thermal comfort according to ISO 7730. The comparison of the systems is based on the categorization according to ISO 7730 and EN 15251.

The target for classroom ventilation systems is a normal level of expectations, which is category II. Maximum $\mathrm{CO}_{2}$ concentrations of $500 \mathrm{ppm}$ above the outside air are therefore permissible.

With the help of the ANSYS Fluent CFD program, the results are evaluated for the fully occupied winter case in a typical German classroom.

All studies stratified ventilation systems have an improved average pollutant removal in the occupied zone, which is greater than $\varepsilon_{o z}=1$, compared to mixing ventilation systems. Centralized systems are most suitable because of the advantageous air supply, which leads to a stable layer boundary of sufficient height and an acceptable draft risk. These systems are recommended in view of the more complex construction measures for the new school buildings.

The wall outlet case is the most suitable stratified ventilation system with the best pollutant removal performance. Due to a ventilation effectiveness of $\varepsilon_{O Z}=$ 1.76 , there is an average $\mathrm{CO}_{2}$ concentration in the occupied zone of $338 \mathrm{ppm}$, which corresponds to category I. After offsetting seat rows in the direction of the windows, classification according to category II is possible for the draught risk.

This also applies to the case with quarter-round displacement ventilation outlets, which has a slightly worse pollutant removal with $\varepsilon_{o z}=1.58$ compared to the case of the wall outlet.

Standing units, which are arranged to the left and right of the blackboard, also ensure good pollutant removal, with $\varepsilon_{o z}=1.61$. With $506 \mathrm{ppm}$, this case leads to best average values of $\mathrm{CO} 2$ concentration of the standing head height. Due to the simple installation requirements, standing units are particularly suitable for the ventilation of classrooms to be renovated. For the time being, however, it is necessary to reduce the draft risk, since the maximum draft risk of $27 \%$ only meets the requirements of category III.

The results of the studied cases also shows that all examined ventilation systems have a slightly cool room climate, which only meets the requirements of category III.

In further investigations, the supply air temperature should be regulated in such a way that the conditions for thermal comfort are in accordance with the requirements of category II. For the optimization of the stratified ventilation systems, the combined evaluation by means of CFD and thermal-energetic building simulations may be appropriate. In addition, the numerically studied cases should be further be investigated or improved with regard to the following points: 
- Experimental validation of the results

- Adjustment of seating arrangements

- Improved mapping of the inflow direction of the supply air outlets

- Extension of the variant study for more boundary conditions

- Reduction of the supply air volume flow by $\frac{1}{\varepsilon_{o z}}$

\section{References}

1. Tiesler, G., H. G. Schönwälder, and F. Ströver.

"Gesundheitsfördernde Einflüsse auf das Leistungsvermögen im schulischen Unterricht." ISFInstitut für interdisziplinäre Schulforschung, Universität Bremen. Forschungsvorhaben im Auftrag des Gemeindeunfallversicherungsverbandes Hannover und der Unfallkasse Hessen (2008).

2. Wargocki, Pawel, and David P. Wyon. "Research report on effects of HVAC on student performance." ASHRAE journal 48.10 (2006): 22.

3. Skistad, H., Mundt, E., Nielsen, P. V., Hagström, K., \& Railio, J. "Displacement ventilation in nonindustrial premises." Guidebook No.1, REHVA (2002).

4. ISO 7730: 2005. "Ergonomics of the thermal environment-Analytical determination and interpretation of thermal comfort using calculation of the PMV and PPD indices and local thermal comfort criteria." 2005.

5. Comite'Europe'en de Normalisation CE. "Energy performance of buildings - Ventilation for buildings - Part 3: For non-residential buildings - Performance requirements for ventilation and room-conditioning systems (Modules M5-1, M5-4)." EN 16798-3. 2017.

6. VDI 6040, Sheet 2, "Air Conditioning of Schools." 2015

7. Comite'Europe'en de Normalisation CE. "Indoor environmental input parameters for design and assessment of energy performance of buildings addressing indoor air quality, thermal environment, lighting and acoustics." EN 15251. 2007.

8. EnEV, Energy Saving Ordinance. "Verordnung über energiesparenden Wärmeschutz und energiesparende Anlagentechnik bei Gebäuden." Bundesgesetzblatt. 2004.

9. Mundt, M., Mathisen, H. M., Moser, M., \& Nielsen, P. V. "Ventilation Effectiveness." Guidebook No.2, REHVA (2004). 